\title{
Effect of Stiffness of Rolling Joints on the Dynamic Characteristic of Ball Screw Feed Systems in a Milling Machine
}

\author{
Dazhong Wang, ${ }^{1}$ Yan Lu, ${ }^{1}$ Tongchao Zhang, ${ }^{2}$ Keyong Wang, ${ }^{1}$ and Akira Rinoshika ${ }^{3}$ \\ ${ }^{1}$ Shanghai University of Engineering Science, Shanghai 201620, China \\ ${ }^{2}$ University of Shanghai for Science and Technology, Shanghai 200093, China \\ ${ }^{3}$ Yamagata University Faculty of Engineering, Yonezawa, Yamagata 992-8510, Japan
}

Correspondence should be addressed to Dazhong Wang; wdzh168@hotmail.com

Received 10 January 2015; Revised 10 April 2015; Accepted 19 April 2015

Academic Editor: Jeong-Hoi Koo

Copyright (C) 2015 Dazhong Wang et al. This is an open access article distributed under the Creative Commons Attribution License, which permits unrestricted use, distribution, and reproduction in any medium, provided the original work is properly cited.

\begin{abstract}
Dynamic characteristic of ball screw feed system in a milling machine is studied numerically in this work. In order to avoid the difficulty in determining the stiffness of rolling joints theoretically, a dynamic modeling method for analyzing the feed system is discussed, and a stiffness calculation method of the rolling joints is proposed based on the Hertz contact theory. Taking a 3-axis computer numerical control (CNC) milling machine set ermined as a research object, the stiffness of its fixed joint between the column and the body together with the stiffness parameters of the rolling joints is evaluated according to the Takashi Yoshimura method. Then, a finite element (FE) model is established for the machine tool. The correctness of the FE model and the stiffness calculation method of the rolling joints are validated by theoretical and experimental modal analysis results of the machine tool's workbench. Under the two modeling methods of joints incorporating the stiffness parameters and rigid connection, a theoretical modal analysis is conducted for the CNC milling machine. The natural frequencies and modal shapes reveal that the joints' dynamic characteristic has an important influence on the dynamic performance of a whole machine tool, especially for the case with natural frequency and higher modes.
\end{abstract}

\section{Introduction}

Ball screw feed drive system has become a key part of CNC machine tools owning to its advantages of high positioning accuracy and transmission efficiency, long operating life, and less internal heat $[1,2]$; therefore its dynamic characteristic has a direct impact on positioning accuracy, processing performance, vibration, and noise characteristic of a machine tool $[3,4]$. The feed system is comprised of ball screw assembly, rolling guide pairs, bearings, workbench, body, and other parts through different kinds of mechanical joints; researches have shown that $30 \%$ to $50 \%$ static stiffness of a machine tool depends on stiffness of joints, more than $90 \%$ damping of a machine tool is derived from joints, and more than $60 \%$ vibration problems that appear on a machine tool originate in joints [5], so dynamic characteristic of the joints is one of the critical factors that influence the dynamic performance of the feed system. Researches on identification methods of joints' stiffness and damping parameters and dynamic characteristic analysis of the feed system are always hot issues in related field.

There are two types of joints in the feed system: fixed joints as bolted joints and rolling joints including ball screw assembly, rolling guide paired, and bearing jointed. So far, the identification methods of joints' dynamic characteristic parameters can be summarized into three kinds: theoretical calculation method, experimental test method, and theoretical calculation combined with experimental test method. As for the fixed joints, [6] proposed general theoretical calculation formulas of the fixed joints' stiffness and damping parameters through experimental data fitting, [7] obtained stiffness and damping parameters of the fixed joint through experimental test, [8] identified the bolted joints' dynamic characteristic parameters through theoretical calculation 
combined with experimental test, and the above methods to identify the fixed joints' stiffness and damping parameters satisfy the requirement of engineering practice appropriately.

As for the identification of rolling joints' dynamic characteristic parameters, [9] took contact angle and contact deformation as variables and theoretically inferred the mathematical expression of ball screw assembly's axial stiffness based on coordinate change principle, [10] obtained parametric model and nonparametric model of the rolling guide pair joint based on the Hertz contact theory and the two-dimensional Chebyshev polynomial separately, [11] calculated dynamic support stiffness of a high-speed motorized spindle bearing based on static and dynamic model of the angular contact bearing, and the theoretical calculation methods in above research have high precision and are suitable for intensive study of the ball screw assembly, rolling guide pair, and bearing's stiffness, but they are too complicated to be applied to stiffness identification of the joints in feed system; [12] measured stiffness and damping parameters of a ball screw assembly by test on a designed experimental platform, [13] developed a measuring device based on the established equivalent single degree of freedom system and identified the dynamic characteristic parameters of the Schneeberger MRC45 linear rolling guide, [14] obtained dynamic characteristic parameters of an angel contact bearing through numerical simulation and experimental test, and the experimental test methods in above researches are accurate and reliable; otherwise, special designed experiment platforms are needed which restricts their universality; therefore it is difficult to apply them to stiffness identification of the joints in feed system. Reference [15-17] identified the dynamic stiffness matrix of the bearing, stiffness and damping parameters of the rolling guide pair for a vertical machining center, and parameters of the ball screw assembly, rolling guide pair for a linear servo system through the combination of theoretical calculation and experimental test. The methods combining theoretical calculation and experimental test in above researches need to obtain frequency response functions (FRFs) of the joints which are difficult to measure sometimes due to restriction of practical mechanical structures; therefore they are not applicable for dynamic characteristic parameters identification of the joints in feed system. It is concluded that there is no method with good accuracy, reliability, and convenience for the dynamic characteristic parameters identification of the joints in feed system.

In allusion to the above problem, with a 3-axis $\mathrm{CNC}$ milling machine taken as research object, this paper discusses the dynamic modeling method of the feed system and proposes a stiffness calculation method of the rolling joints based on the Hertz contact theory. A finite element model of the CNC milling machine is established, and the correctness of the FE model and the stiffness calculation method of the rolling joints are verified by the comparison of theoretical and experimental modal analysis of machine workbench. On this basis, under the two modelling methods of the joints taking stiffness into consideration and connecting joints rigidly, theoretical modal analysis of the CNC milling machine is implemented, respectively, and the results are compared and analyzed.

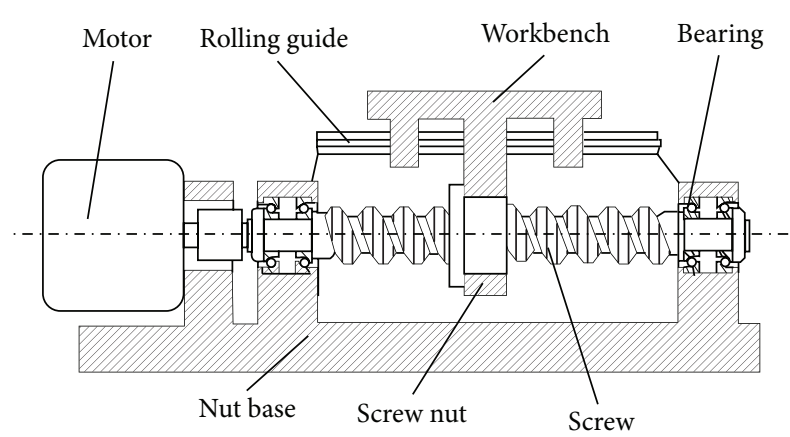

FIGURE 1: Structure diagram of the feed system.

\section{Dynamic Modeling of Feed System}

Typical structure of a CNC machine tool feed system [18] is shown in Figure 1, an AC (Alternating Current) servo motor drives the ball screw to rotate by connection of the coupling, then the rotary motion is converted to linear motion through the screw nut, and finally the workbench implements its straight feed motion supported by four rolling guide pairs. The screw is supported by the left bearing pack and the right bearing pack, and the frequently used support mode of the screw in horizontal feed system is supported fixed at one end and simply supported at the other while it is supported fixed at both ends in vertical feed drive system. The ball screw assembly, rolling guide pairs, and bearings have been pretightened, and the screw has been prestretched and applied with a preloading torque.

The fixed joints in the feed system mainly include bolted joints between workbench and slide block, between workbench and nut base, between body and bearing base, and between body and motor base, while the rolling joints mainly include the joints of ball screw assembly, rolling guide pair, and bearing. The most common method for modeling the joints is to substitute several spring-damping units for the connection between joints' substructures.

In order to establish the dynamic model of feed system more conveniently, the fixed joints can be simplified as rigid connection on account of their high stiffness. Although the AC servo motor, screw, bearings and other related parts are not modeled in the analysis, their axial stiffness is carefully incorporated. Based on the above simplified conditions, dynamic modeling method of the feed system [3] is as shown in Figure 2. Considering that damping parameters have tiny effect on natural frequency, thus the user-defined MATRIX27 stiffness element in ANSYS software is utilized to simulate the contact characteristic of joints. The workbench is connected to the saddle with four parallel MATRIX27 stiffness elements, among which the stiffness of $Z$ direction $K_{z}$ stands for the normal stiffness of rolling guide pair, the stiffness of $Y$ direction $K_{y}$ denotes the tangential stiffness of rolling guide pair, and the stiffness of $X$ direction $K_{x}$ equals 25 percent of axial feed unit's equivalent stiffness constituted by the left bearing pack, the ball screw assembly, and the right bearing pack. 


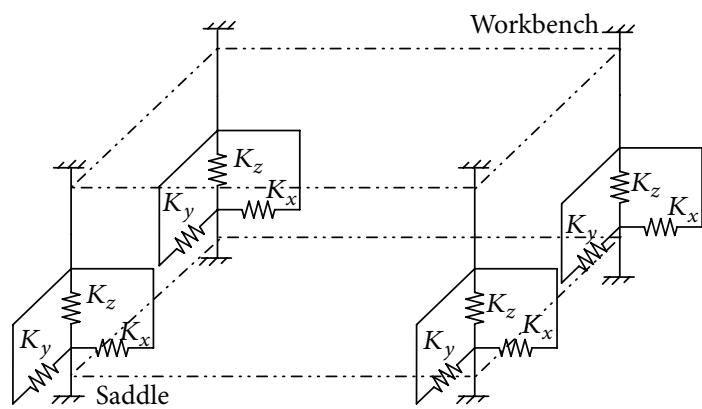

Figure 2: Dynamic modeling of the feed system.

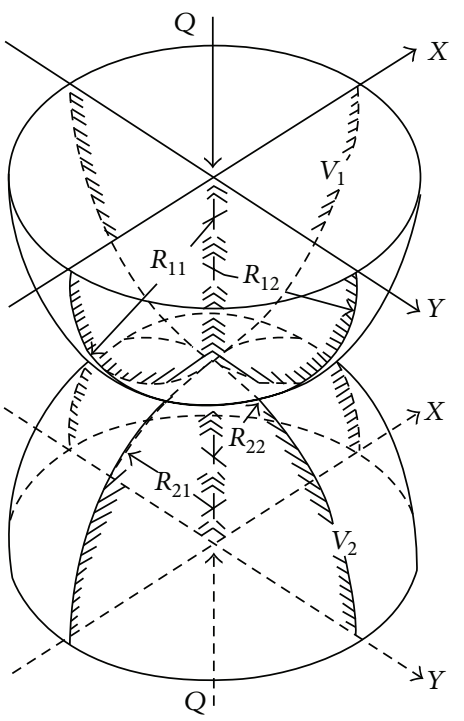

Figure 3: Hertz contact model.

\section{Stiffness Calculation Method of Rolling Joints}

3.1. Hertz Contact Theory. Hertz contact theory is the classical theory to calculate contact deformation and contact stress of elastic body. As shown in Figure 3, two elastic objects $V_{1}$ and $V_{2}$ resist each other under the pressure of external force $Q$, and the two objects satisfy the following assumptions [19]: materials of the two objects are homogeneous and isotropic; contact surface is so smooth that there is no tangential friction force existing at contact area; the contact objects only produce elastic deformation that obeys the Hooke law; size of the contact surface is very small compared with the objects' curvature radius. Therefore, in the center of contact area, approaching distance resulting from the two objects that resist each other is [3]

$$
\delta=\frac{K}{\pi a}\left(\frac{3 Q}{2}\left(\frac{1-u_{1}^{2}}{E_{1}}+\frac{1-u_{2}^{2}}{E_{2}}\right)\right)^{2 / 3}\left(\sum \rho\right)^{1 / 3}
$$

where $K$ and $a$ are Hertz coefficients, which can be obtained by looking up tables in reference; $u_{1}$ and $u_{2}$ are Poisson ratio of the two contact objects; $E_{1}$ and $E_{2}$ are elastic modulus of the two contact objects; $\sum \rho$ is the synthetic curvature at

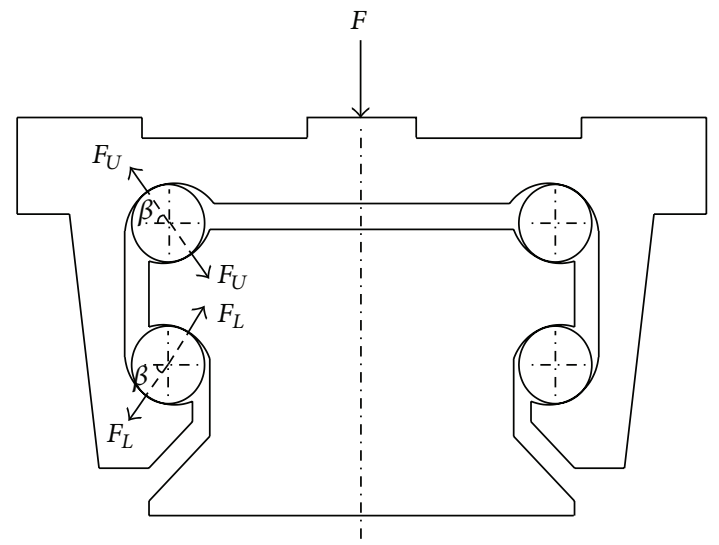

FIGURE 4: Force analysis of rolling guide joint.

contact point; namely, $\sum \rho=\sum_{i=1}^{2} \sum_{j=1}^{2}\left(1 / R_{i j}\right)$, where $R_{i j}(i=$ $1,2 ; j=1,2)$ are principal curvatures of the object $V_{i}$.

As for the rolling joints of ball screw assembly, rolling guide pairs, and bearings in the feed system, the common feature is that they all contain the contact between ball and groove; therefore the stiffness of rolling joints in feed system can be calculated based on the Hertz contact theory.

3.2. Stiffness of Rolling Guide Pair. Rolling guide pair is comprised of slide block, balls, guides, and so on, assuming that the contacts between ball and slide block groove, between ball and guide groove satisfy the four conditions of the Hertz contact theory; in addition, load is evenly distributed among each backing ball in the same row; then the normal and tangential stiffness of the rolling guide pair can be calculated based on the Hertz contact theory.

Typical structure of the rolling guide pair [3] is shown in Figure 4; there are four balls in joint, total number of the backing balls is $z$, and pressure angle of the contact between ball and groove is $\beta$. Under the pressure of external force $F$, normal reaction of each ball at up row is $F_{U}$, and normal reaction of each ball at low row is $F_{L}$. In general, each ball is in compression owning to pretightened force, so the vertical force equilibrium of the slide block is $F+z F_{L} \sin \beta / 2=$ $z F_{U} \sin \beta / 2$.

Assuming that the pretightened force $F_{0}$ is evenly distributed between all backing balls, normal force and initial deformation of each ball induced by pretightened force are $P_{0}$ and $\delta_{0}$, and the relationship between $P_{0}$ and $F_{0}$ is $F_{0}=$ $\sqrt{2} z P_{0} \sin \beta$. Under the pressure of external force $F$, the deformation of each ball at up row is $\delta_{u}$, the deformation of each ball at low row is $\delta_{L}$, and vertical displacement of slide block is $\delta_{n}$; thus the compatibility equation of deformation is $\left(\delta_{u}-\delta_{0}\right) \sin \beta=\left(\delta_{0}-\delta_{L}\right) \sin \beta=\delta_{n}$. Initial deformation $\delta_{0}$ can be obtained from (1), and $\delta_{U}=f_{U}\left(F_{U}\right), \delta_{L}=f_{L}\left(F_{L}\right)$. Therefore, normal stiffness of the rolling guide pair can be obtained as $K_{n}=F / \delta_{n}$. Slide block is not subject to additional tangential load, so tangential displacement of the slide block relative to the guide rail is $\delta_{\tau}=\left(\delta_{u}-\delta_{0}\right) \cos \beta$. Therefore tangential stiffness of the rolling guide pair can be calculated as $K_{\tau}=z P_{0} \cos \beta / 2 \delta_{\tau}$ [3]. 


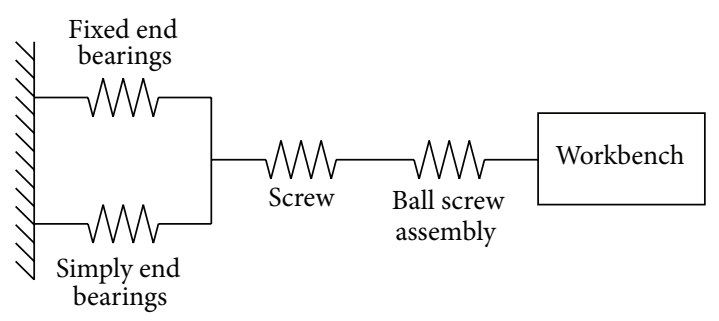

FIGURE 5: Dynamic model of ball screw feed unit.

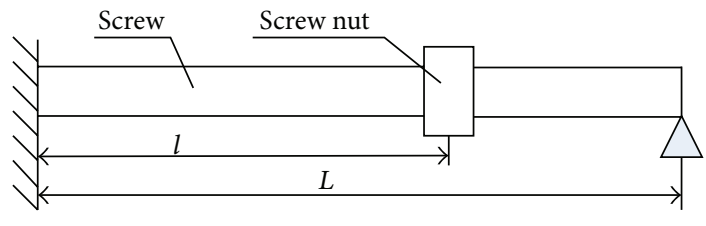

FIGURE 6: Schematic diagram of screw support mode.

3.3. Equivalent Stiffness of Axial Feed Unit. Dynamic model of the axial feed unit is shown in Figure 5; equivalent axial stiffness $k_{x}$ is the synthesis of bearings axial stiffness, screw axial stiffness, and ball screw assembly axial stiffness. The axial stiffness of the deep groove ball bearing used at the simple end of screw is so small that can be neglected, so $1 / k_{x}=1 / k_{s}+1 / k_{a}+1 / k_{b}[3]$, where $k_{s}$ is screw axial stiffness; $k_{a}$ is ball screw assembly axial stiffness; $k_{b}$ is bearings axial stiffness.

3.3.1. Screw Axial Stiffness. The screw is supported fixed at one end and simply supported at the other, which is shown in Figure 6. Screw axial stiffness can be calculated based on mechanics of materials as $k_{s}=\pi d^{2} E / 4 l$, where $d$ is minor diameter of the screw thread; $E$ is elasticity modulus of the screw; $l$ is distance between the screw nut and the fixed end. The workbench and the saddle are usually located at the midpoint of travel range, without loss of generality, the stiffness of the screw nut located at mid-point of screw is taken as its axial support stiffness; namely, $k_{s}=\pi d^{2} E / 2 L$.

3.3.2. Ball Screw Assembly Axial Stiffness. Ball screw assembly is comprised of screw, balls, screw nut, and so on, assuming that the contacts between ball and screw groove, between ball and screw nut groove satisfy the four conditions of the Hertz contact theory; in addition (1) centrifugal force and gyroscopic moment induced by balls rotation are so small that can be ignored; (2) axial load is evenly distributed between all backing balls; thus ball screw assembly axial stiffness can be calculated based on the Hertz contact theory.

Ball screw assembly of feed system is pretightened by applying a preload, and external axial load can be neglected; force analysis of the ball screw assembly under the force of preload $F_{a}$ [3] is shown in Figure 7. Normal reaction of each ball is $P$, pressure angle of the contact between ball and groove is $\beta$, deformation of the contact between ball and nut groove is $\delta_{1}$, and deformation of the contact between ball and screw groove is $\delta_{2}$. The axial force equilibrium of the screw nut is

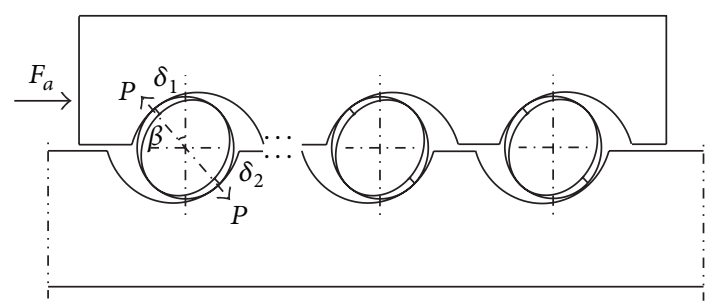

FIGURE 7: Force analysis of ball screw joint.

$F_{a}-P z \sin \beta \cos \phi=0$, where $z$ is total number of backing balls; $\phi$ is lead angle of the screw. It is calculated from (1) that

$$
\begin{array}{r}
\delta_{i}=\frac{K_{i}}{\pi a_{i}}\left(\frac{3 P}{2}\left(\frac{1-u_{1}^{2}}{E_{1}}+\frac{1-u_{2}^{2}}{E_{2}}\right)\right)^{2 / 3}\left(\sum \rho_{i}\right)^{1 / 3}, \\
i=1,2 .
\end{array}
$$

Synthetic curvature at contact point between each ball and screw nut groove and synthetic curvature at contact point between each ball and screw groove are [3]

$$
\begin{aligned}
& \sum \rho_{1}=\frac{2}{d_{b}}+\frac{2}{d_{b}}-\frac{1}{d_{b} f_{1}}-\frac{2 \cos \alpha \cos \phi}{d+d_{b} \cos \alpha} \\
& \sum \rho_{2}=\frac{2}{d_{b}}+\frac{2}{d_{b}}-\frac{1}{d_{b} f_{2}}+\frac{2 \cos \alpha \cos \phi}{d-d_{b} \cos \alpha}
\end{aligned}
$$

where $d_{b}$ is diameter of ball; $f_{1}$ is a form factor, namely, the ratio of screw nut groove's curvature radius to ball radius; $f_{2}$ is the ratio of screw groove's curvature radius to ball radius. Axial displacement of screw nut to screw can be obtained from geometrical relationship that $\delta_{a}=\left(\delta_{1}+\delta_{2}\right) / \sin \beta \cos \phi$. Ball screw assembly axial stiffness can be obtained by solving simultaneous (2)-(3) that $K_{a}=F_{a} / \delta_{a}$.

3.3.3. Bearing Axial Stiffness. Bearing is comprised of inner ring, balls, outer ring, and so on. Assuming that the contacts between ball and inner ring, between ball and outer ring satisfy the four conditions of the Hertz contact theory; in addition (1) centrifugal force and gyroscopic moment induced by ball rotation are so small that can be ignored; (2) axial load is evenly distributed between all backing balls; thus bearing axial stiffness can be calculated based on the Hertz contact theory.

Taking the angular contact bearings used at fixed end as an example, the pretightened force $F_{a}$ is applied on bearings, additional axial and radial forces induced by screw can be neglected, and force analysis of bearings [3] is shown in Figure 8. Pressure angle of the contact between ball and groove is $\beta$, normal reaction of each ball is $P$, number of balls in one bearing is $z$, deformation of the contact between ball and outer groove is $\delta_{1}$, and deformation of the contact between ball and inner groove is $\delta_{2}$; thus the axial force 


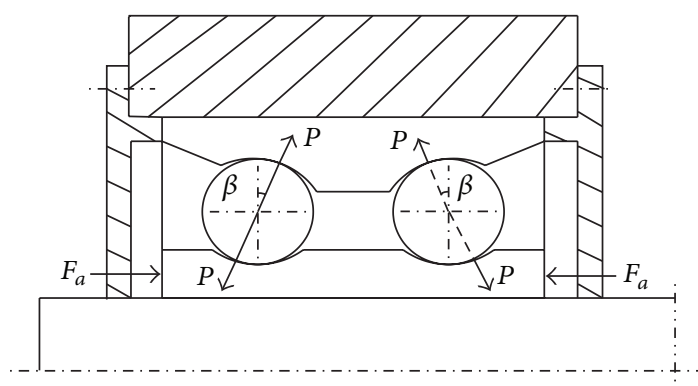

FIGURE 8: Force analysis of bearing joint.

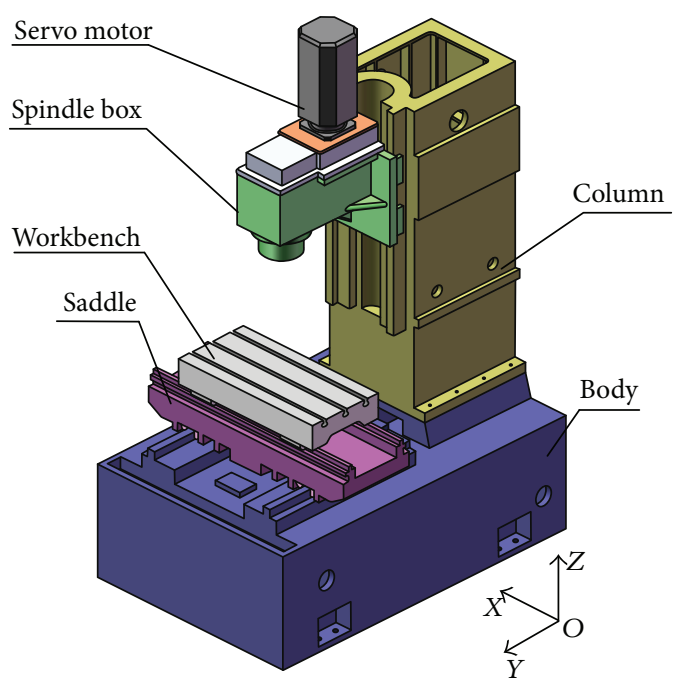

FIGURE 9: Structure diagram of CNC milling machine.

equilibrium of each bearing is $F_{a}-z P \sin \beta=0$. It is calculated from (1) that

$$
\begin{array}{r}
\delta_{i}=\frac{K_{i}}{\pi a_{i}}\left(\frac{3 P}{2}\left(\frac{1-u_{1}^{2}}{E_{1}}+\frac{1-u_{2}^{2}}{E_{2}}\right)\right)^{2 / 3}\left(\sum \rho_{i}\right)^{1 / 3} \\
i=1,2
\end{array}
$$

where the meaning of each parameter in (4) is identical with that in (2). Axial displacement of bearings to screw can be obtained from geometrical relationship that $\delta_{a}=\left(\delta_{1}+\right.$ $\left.\delta_{2}\right) \sin \beta$. Bearing axial stiffness can be obtained by solving simultaneous (4) as $k_{b}=F_{a} / \delta_{a}$.

\section{Finite Element Modeling}

A CNC milling machine with three axes, $X, Y$, and $Z$, is determined as research object, its structure is shown in Figure 9, and three feed systems exist between column and spindle box, between body and saddle, and between saddle and workbench, respectively.

4.1. Stiffness Calculation of Fixed Joint. In order to establish FE model of the milling machine more easily, bolted joint between column and body is emphasized while the fixed joints between guide and body, between slide block and
TABLE 1: Stiffness of bolted joints and parameters of stiffness elements.

\begin{tabular}{lccc}
\hline Direction & Stiffness $(\mathrm{N} / \mathrm{m})$ & $\begin{array}{c}\text { Number of } \\
\text { stiffness } \\
\text { elements }\end{array}$ & $\begin{array}{c}\text { Parameters of } \\
\text { stiffness } \\
\text { elements }\end{array}$ \\
\hline Normal & $5.07 \times 10^{10}$ & 16 & $3.12 \times 10^{9}$ \\
Tangential & $2.02 \times 10^{10}$ & 16 & $1.26 \times 10^{9}$ \\
\hline
\end{tabular}

workbench, and between servo motor and spindle box are connected rigidly with MPC184 element in ANSYS.

Takashi Yoshimura studied bolted joints in machine tools. It was concluded that all these joints possess the same dynamic characteristic data per unit area if the average contact pressures at fixed joints are equal. As for the bolted joint between column and body, the contact pressure can be considered as being uniformly distributed when neglecting the influence of bolts distribution and structures physical deformation. Therefore, stiffness of the bolted joints can be obtained through calculating contact pressure and the Takashi Yoshimura method. The column is connected to the body with 16 parallel MATRIX27 stiffness elements; stiffness of the bolted joints and parameters of the stiffness elements are shown in Table 1.

4.2. Stiffness Calculation of Rolling Joints in Feed System. Stiffness of the rolling joints in $X, Y$, and $Z$ feed systems can be obtained based on the proposed method in Section 3. Support mode of the screw in $X$ and $Y$ feed systems is supported fixed at one end and simply supported at the other, among which a couple of angular contact bearings are used at the fixed end and a deep groove ball bearing is used at the simply supported end; support mode of the screw in $Z$ feed system is supported fixed at both ends, among which a centeroriented thrust ball bearing is used at each end. The calculated stiffness of rolling joints in $X, Y$, and $Z$ feed systems is shown in Tables 2, 3, and 4, respectively.

4.3. Finite Element Modeling of Milling Machine. Geometric model of the CNC milling machine is built and then is transmitted to HyperMesh to establish its finite element model, during which some points should be focused on as follows:

(1) Simplifying Geometric Model. In order to obtain more reasonable element shape generated by meshing and improve the accuracy and efficiency of calculation and analysis, the geometric model is simplified before building finite element model as follows: little bolt holes and other process holes are neglected; filleting and chamfering are straight lined; motors and other components that have little effect on calculation result are ignored; equivalent mass blocks are substituted for complicated parts inside of the spindle box.

(2) Finite Element Meshing. Element type of the whole model is chosen as Solid92, which is a tetrahedral element with 10 nodes; about 29.4 million Solid92 elements are obtained by meshing. 


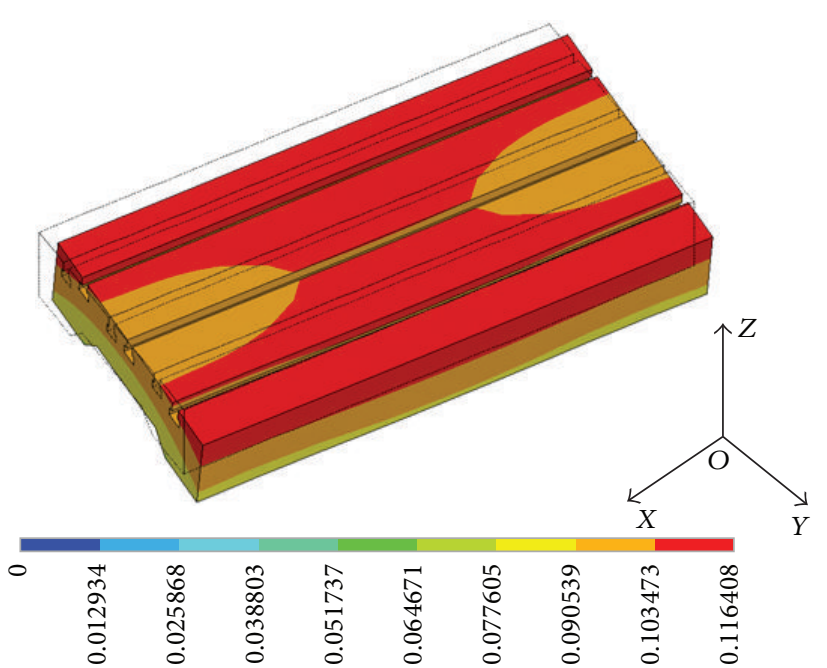

(a) The 1st vibration mode

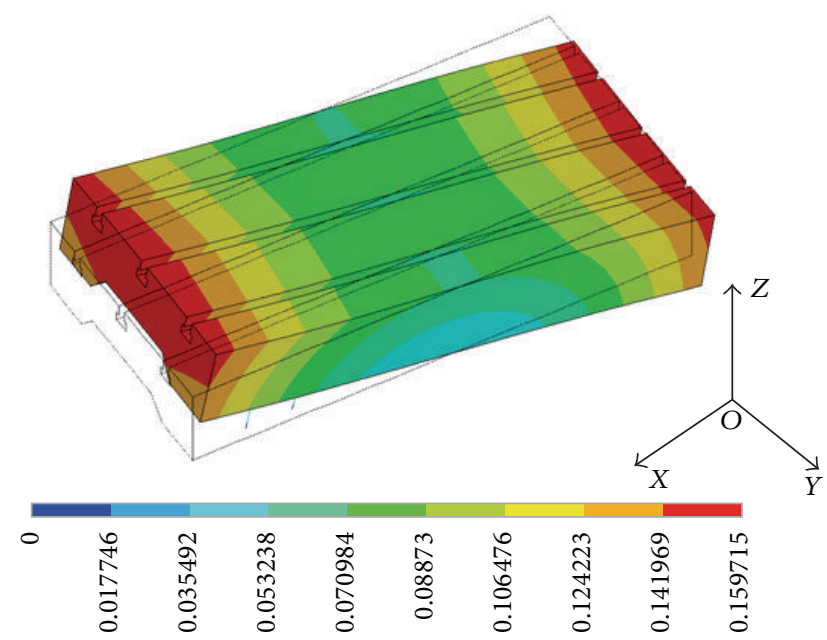

(c) The 3rd vibration mode

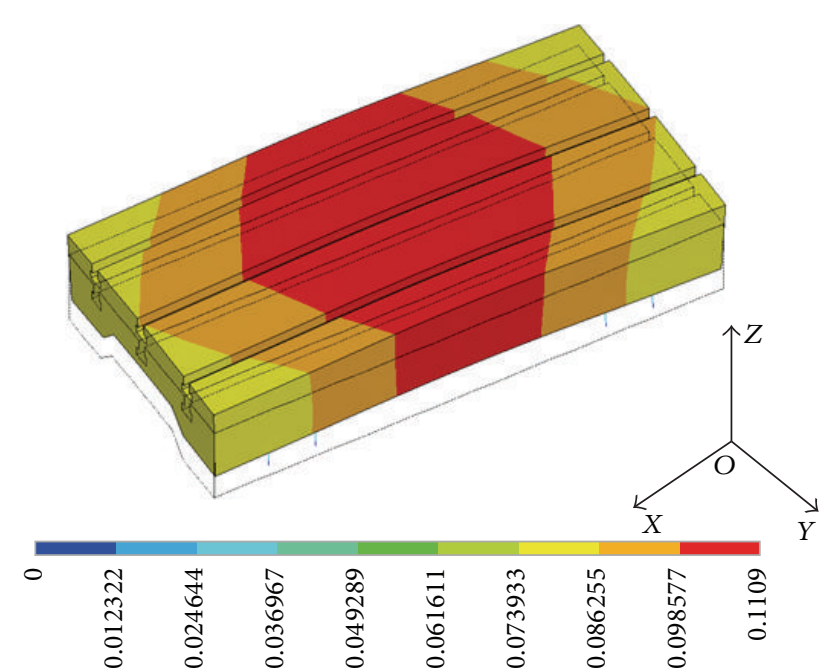

(b) The 2nd vibration mode

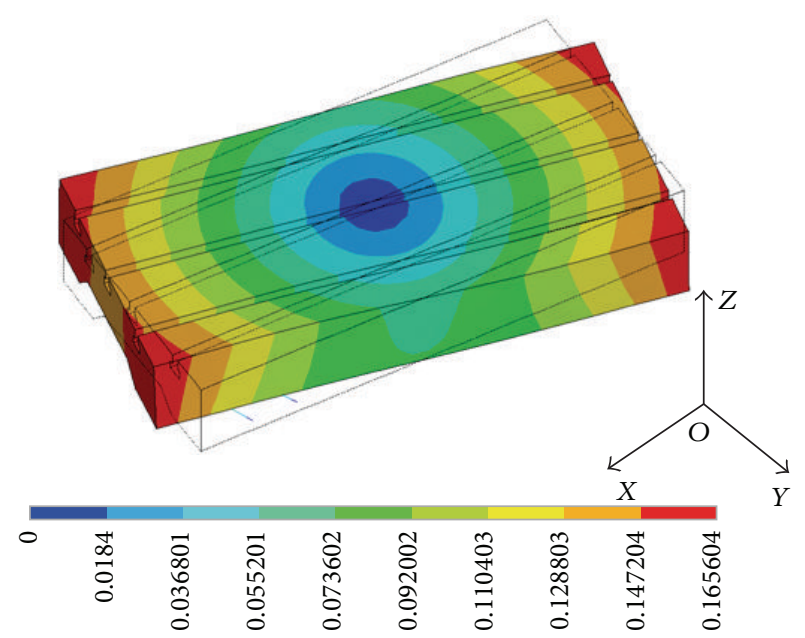

(d) The 4th vibration mode

FIGURE 10: Theoretical vibration modes of workbench.

TABLE 2: Stiffness of rolling joints in $X$ feed system.

\begin{tabular}{|c|c|c|c|c|c|}
\hline $\begin{array}{l}\text { Normal stiffness of } \\
\text { rolling guide } K_{z} \\
\text { (N/um) }\end{array}$ & $\begin{array}{l}\text { Tangential stiffness of } \\
\text { rolling guide } K_{y} \\
\text { (N/um) }\end{array}$ & $\begin{array}{l}\text { Axial stiffness of } \\
\text { screw } k_{s}(\mathrm{~N} / \mathrm{um})\end{array}$ & $\begin{array}{l}\text { Stiffness of ball screw } \\
k_{a}(\mathrm{~N} / \mathrm{um})\end{array}$ & $\begin{array}{c}\text { Axial stiffness of } \\
\text { bearings } k_{b}(\mathrm{~N} / \mathrm{um})\end{array}$ & $\begin{array}{c}\text { Axial equivalent } \\
\text { stiffness } K_{x}(\mathrm{~N} / \mathrm{um})\end{array}$ \\
\hline 156 & 112 & 443 & 290 & 503 & 130 \\
\hline
\end{tabular}

TABle 3: Stiffness of rolling joints in $Y$ feed system.

\begin{tabular}{|c|c|c|c|c|c|}
\hline $\begin{array}{l}\text { Normal stiffness of } \\
\text { rolling guide } K_{z} \\
\text { (N/um) }\end{array}$ & $\begin{array}{l}\text { Tangential stiffness of } \\
\text { rolling guide } K_{y} \\
\text { (N/um) }\end{array}$ & $\begin{array}{l}\text { Axial stiffness of } \\
\text { screw } k_{s}(\mathrm{~N} / \mathrm{um})\end{array}$ & $\begin{array}{c}\text { Stiffness of ball screw } \\
k_{a}(\mathrm{~N} / \mathrm{um})\end{array}$ & $\begin{array}{c}\text { Axial stiffness of } \\
\text { bearings } k_{b}(\mathrm{~N} / \mathrm{um})\end{array}$ & $\begin{array}{c}\text { Axial equivalent } \\
\text { stiffness } K_{x}(\mathrm{~N} / \mathrm{um})\end{array}$ \\
\hline 182 & 131 & 591 & 290 & 503 & 141 \\
\hline
\end{tabular}

TABLE 4: Stiffness of rolling joints in $Z$ feed system.

\begin{tabular}{|c|c|c|c|c|c|}
\hline $\begin{array}{l}\text { Normal stiffness of } \\
\text { rolling guide } K_{z} \\
\text { (N/um) }\end{array}$ & $\begin{array}{c}\text { Tangential stiffness of } \\
\text { rolling guide } K_{y} \\
(\mathrm{~N} / \mathrm{um})\end{array}$ & $\begin{array}{l}\text { Axial stiffness of } \\
\text { screw } k_{s}(\mathrm{~N} / \mathrm{um})\end{array}$ & $\begin{array}{c}\text { Stiffness of ball screw } \\
k_{a}(\mathrm{~N} / \mathrm{um})\end{array}$ & $\begin{array}{l}\text { Axial stiffness of } \\
\text { bearing } k_{b}(\mathrm{~N} / \mathrm{um})\end{array}$ & $\begin{array}{c}\text { Axial equivalent } \\
\text { stiffness } K_{x}(\mathrm{~N} / \mathrm{um})\end{array}$ \\
\hline 167 & 120 & 752 & 165 & 373 & 225 \\
\hline
\end{tabular}




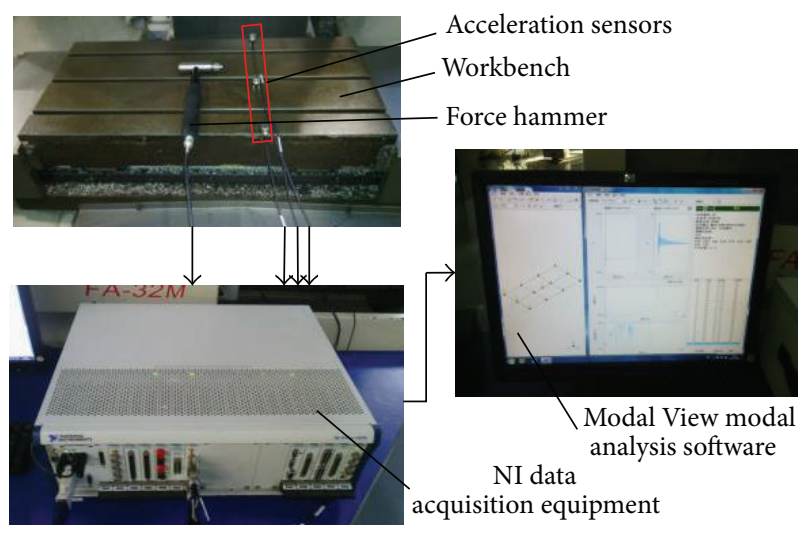

FIGURE 11: Working principle of modal testing system.

(3) Modeling of Joints. According to the dynamic modeling method of the joints and the stiffness parameters calculated based on the proposed method, 28 MATRIX27 elements are used for modeling the joints in $X, Y$, and $Z$ feed systems.

(4) Boundary Conditions. In accordance with the practical constraint conditions of the CNC milling machine, all DOF (Degrees of Freedom) of the nodes at junction area between the body and the ground are constrained; the established FE model of the whole machine is shown in Figure 9.

\section{Verification of the FE Model}

In order to verify the validity of the finite element model established above, theoretical and experimental modal analysis of the workbench are conducted. The finite element model of the workbench taking joints' stiffness parameters into consideration is transmitted to ANSYS software, theoretical modal calculation is accomplished based on the Block Lanczos algorithm, and the first four orders natural frequencies and modal shapes are shown in Table 5 and Figure 10 separately.

The hammering method with single-point exciting and multipoints vibration picking is used to conduct experiment modal test. Working principle of modal testing system is shown in Figure 11. Test equipment mainly used in experiment includes Kistler 9724 force hammer, three BK 4525B triaxial micro accelerations, and NI PXIe-1075 data collection system with NI PXIe-4498 dynamic signal acquisition module, and the modal analysis software Modal View is used to complete data collection and processing.

A workbench structure model with measuring points arrangement is built in Modal View as shown in Figures 12 and 13, measure points are set up in the model, and hammering position is fixed at the ninth point.

Basic process of modal test includes workbench, acquisition and processing of input and output signal, calculation of frequency response functions, and identification of modal parameters.

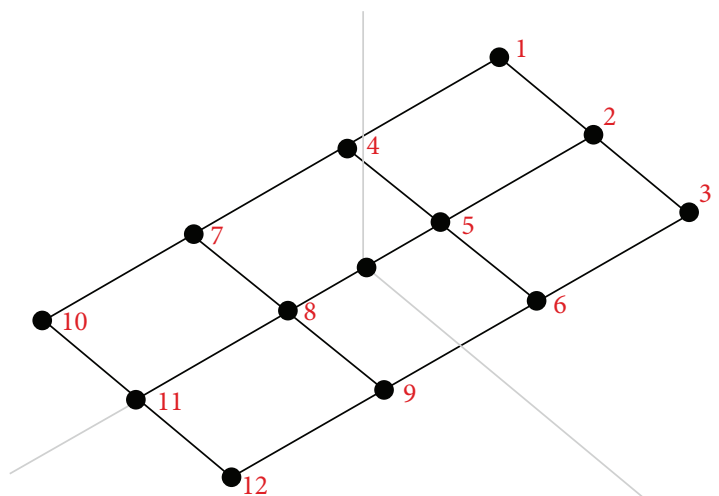

FIGURE 12: Measuring points arrangement of workbench.

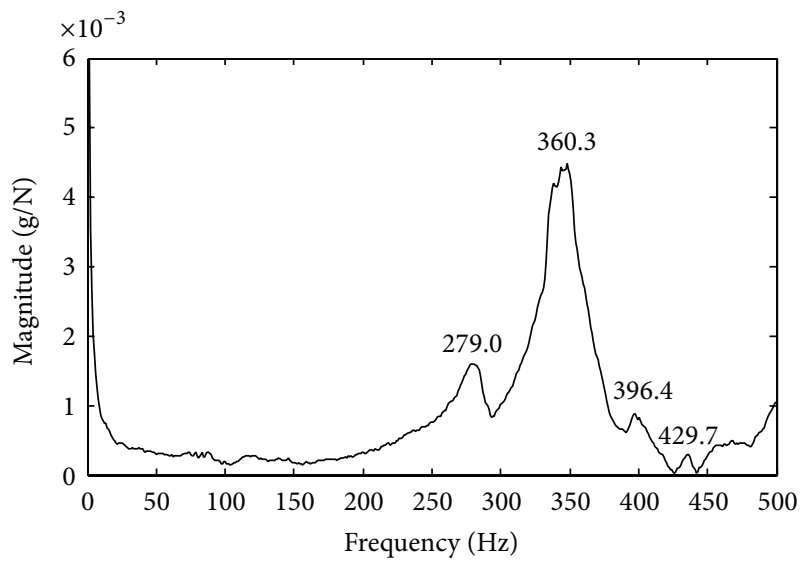

FIgURE 13: A group of measured frequency response functions.

TABLE 5: Comparison of theoretical natural frequencies and experimental natural frequencies.

\begin{tabular}{lcccc}
\hline Modal orders & 1 & 2 & 3 & 4 \\
\hline Measured results (Hz) & 279.0 & 360.3 & 396.4 & 429.7 \\
Throretical results (Hz) & 281.9 & 363.1 & 388.6 & 417.5 \\
Relative error (\%) & -1.03 & -0.77 & 2.07 & 2.92 \\
\hline
\end{tabular}

When the workbench is located at the neutral position, a group of measured FRF is shown in Figure 13, and the first four orders natural frequencies and modal shapes are shown in Table 5 and Figure 14 separately.

It can be seen from Figures 10 and 14 that the 1st vibration mode of the workbench is swing vibration around $X$-axis, the 2 nd vibration mode is bending vibration, the 3 rd vibration mode is swing vibration around the $Y$-axis, and the 4 th vibration mode is yawing vibration around the $Z$-axis. Theoretical modal vibration modes are completely in conformity with experimental modal vibration modes. The comparison of the first 4 orders theoretical natural frequencies and experimental natural frequencies is shown in Table 5; it is clearly demonstrated that the theoretical natural frequencies agree well with the measured natural frequencies, and the maximum relative error is $2.92 \%$. 


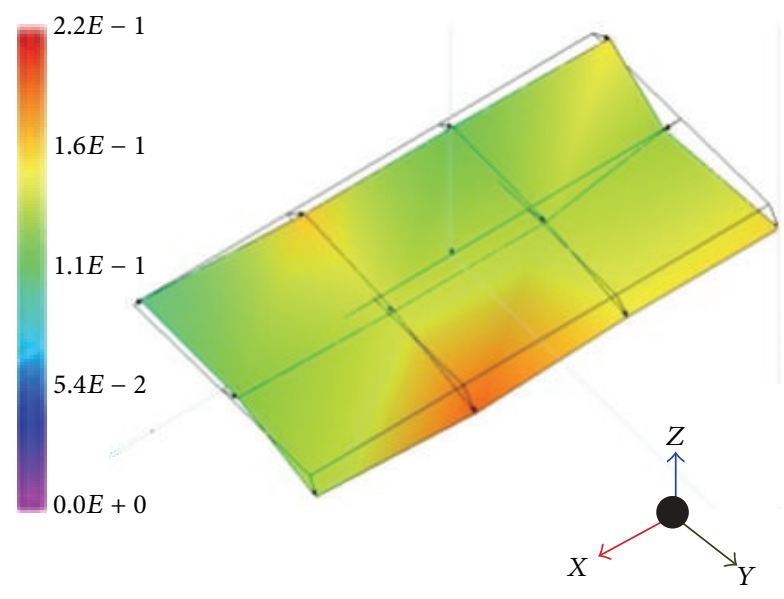

(a) The 1st vibration mode

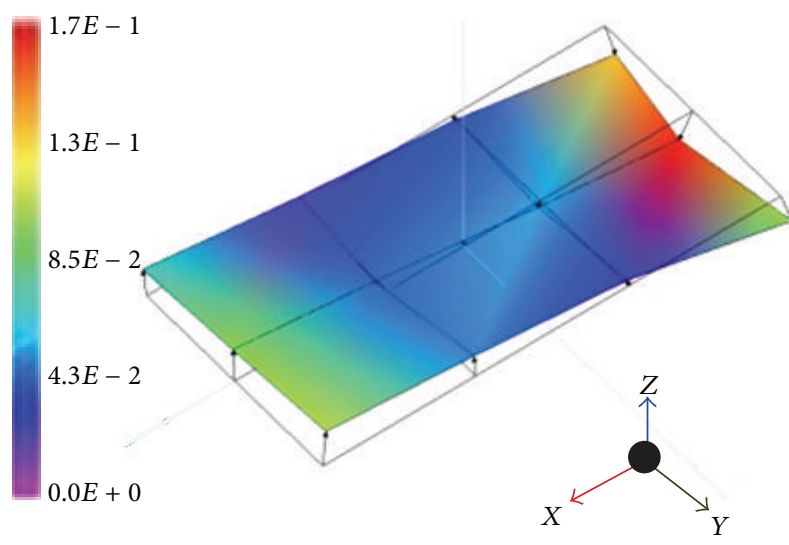

(c) The 3rd vibration mode

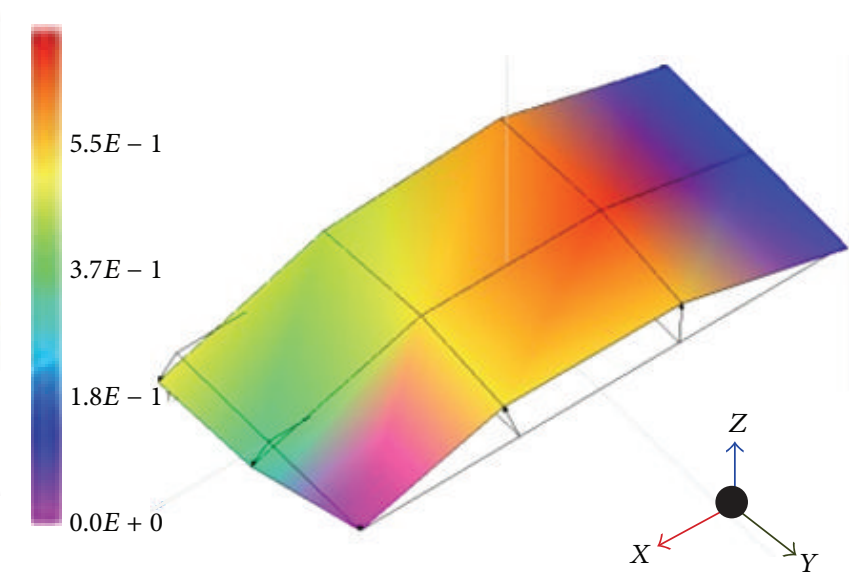

(b) The 2nd vibration mode

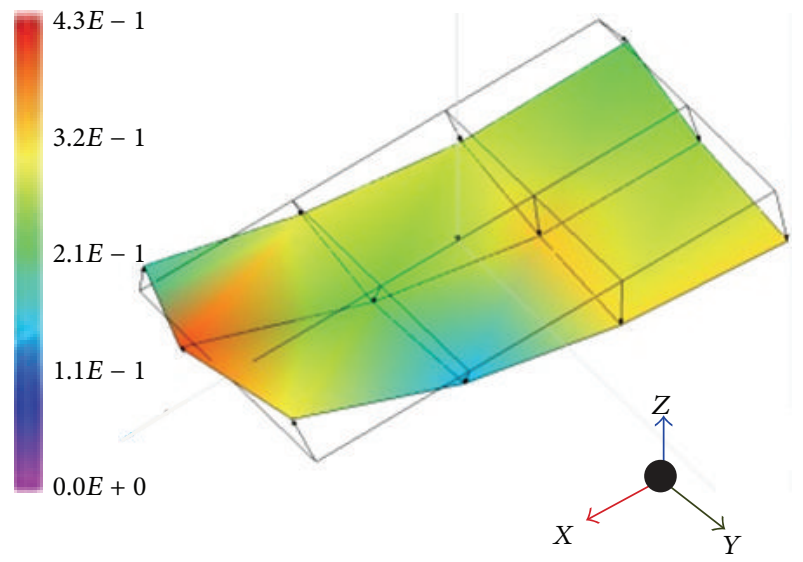

(d) The 4th vibration mode

FIGURE 14: Experimental vibration modes of workbench.

The correctness of the finite element model is verified by the comparison of theoretical natural frequencies and modal shapes and their corresponding experimental results, which also indicates that the stiffness calculation method proposed in this paper is right and feasible.

\section{Dynamic Characteristic Analysis of CNC Milling Machine}

The finite element model of the CNC milling machine is transmitted to ANSYS for modal calculation; the first four orders natural frequencies and modal shapes of the whole machine tool are shown in Table 6 and Figure 15 separately.

It can be seen from Figure 15 that the 1st vibration mode of the machine tool is low order pitching vibration of the spindle and the column, the 2 nd vibration mode is swing vibration of the spindle and the column around $X$-axis, the 3 rd vibration mode is high order pitching vibration of the spindle and the column, and the 4 th vibration mode is swing vibration of the workbench and the saddle around $X$-axis.

Furthermore, regardless of joints' stiffness parameters and connecting joints rigidly in finite element model with MPC184 element, theoretical modal calculation is conducted
TABLE 6: Comparison of natural frequencies under the two modeling methods of joints.

\begin{tabular}{lcccc}
\hline Modal orders & 1 & 2 & 3 & 4 \\
\hline Flexible connection $(\mathrm{Hz})$ & 44.4 & 49.4 & 85.5 & 98.2 \\
Rigid connection $(\mathrm{Hz})$ & 66.8 & 69.8 & 160.0 & 178.8 \\
Absolute error $(\mathrm{Hz})$ & 22.4 & 20.1 & 74.5 & 80.6 \\
\hline
\end{tabular}

on the model with rigid connection; the first four orders natural frequencies and modal shapes are shown in Table 6 and Figure 16 separately.

It can be seen from Figure 16 that the 1st vibration mode of the machine tool is low order pitching vibration of the spindle and the column, the 2 nd vibration mode is swing vibration of the spindle and the column around $X$-axis, the 3 rd vibration mode is high order pitching vibration of the spindle, and the 4 th vibration mode is swing vibration of the spindle around $Z$-axis.

The first four orders vibration modes of the whole machine tool have great difference under the two modeling methods of joints. Vibration modes considering joints stiffness mainly present as local vibration of the spindle 


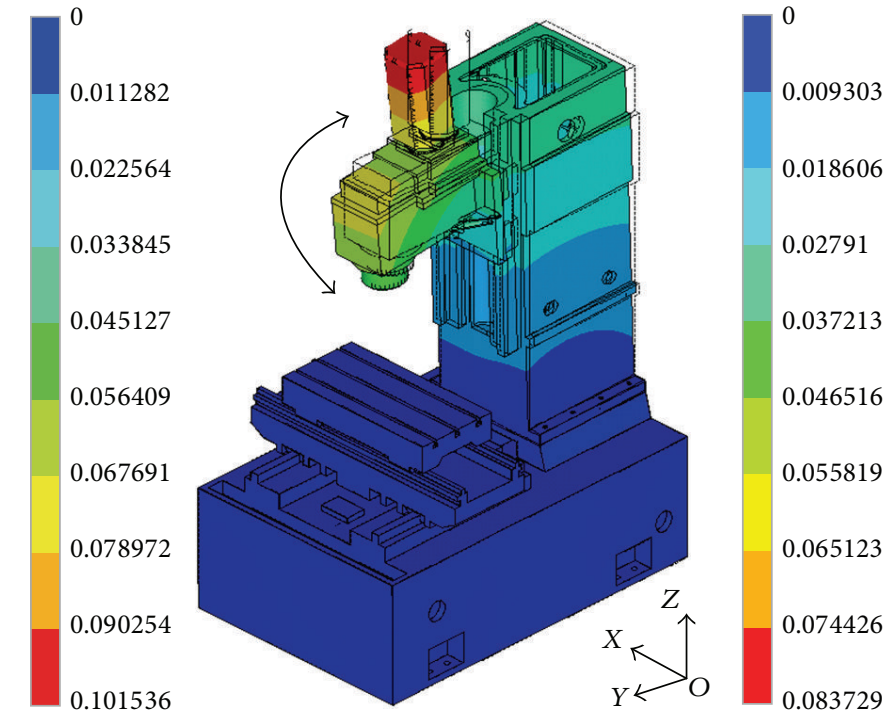

(a) The 1st vibration mode
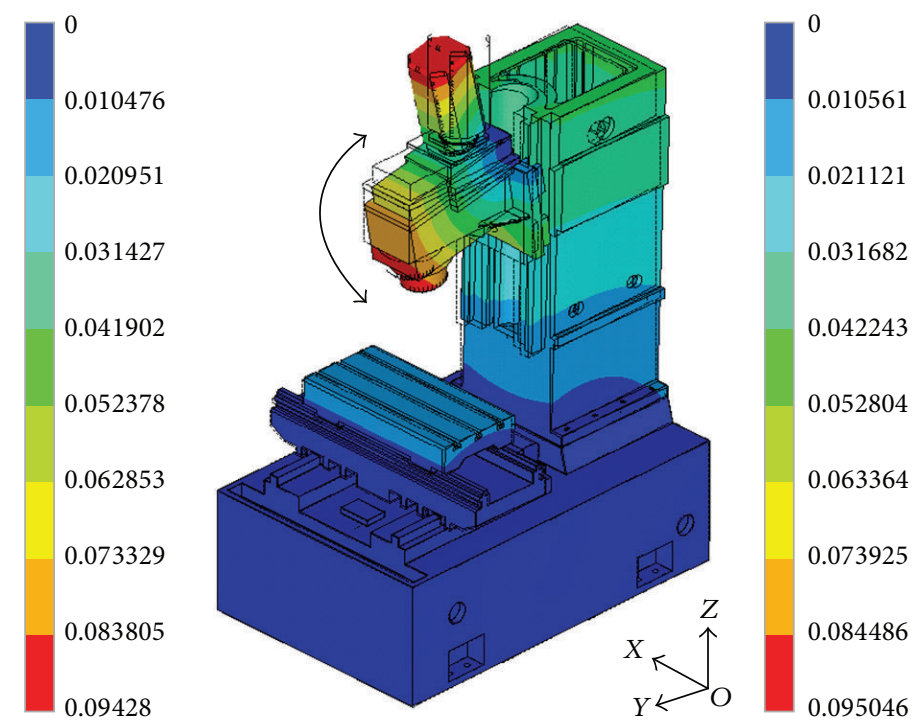

(c) The 3rd vibration mode

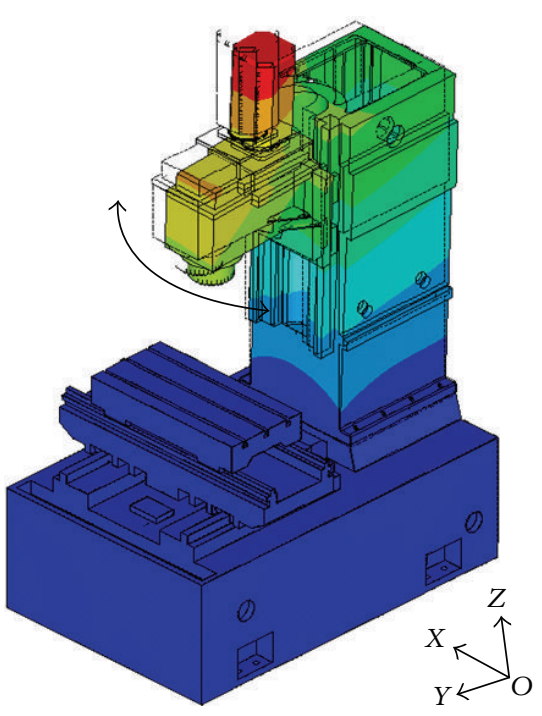

(b) The 2nd vibration mode

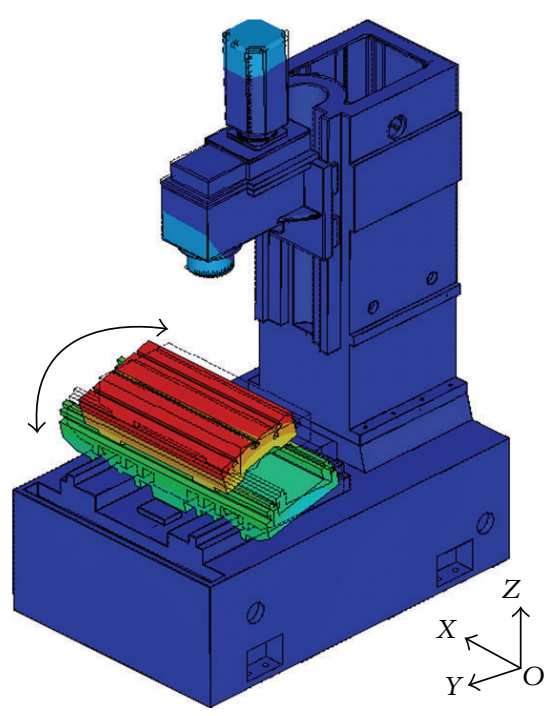

(d) The 4th vibration mode

FIGURE 15: Vibration modes of the whole machine on side ring stiffness.

box, the saddle, and the workbench, while vibration modes connecting joints rigidly focus on the overall vibration of the column and the spindle box, the saddle, and the workbench.

Comparison of the first orders natural frequencies is shown in Table 6; it is clearly shown that the error of natural frequencies between the two modeling methods is quite big, and the error increases significantly along with the ascending of modal orders.

The comparison of natural frequencies and modal shapes indicates that joint's dynamic characteristic is one of the key factors that influence the dynamic performance of machine tool, and the influence is much more significant when it comes to high order natural frequencies. Therefore, calculating stiffness parameters of joints in feed system accurately at designing stage of the machine tool is of decisive significance in obtaining right theoretical analysis results.

\section{Conclusions}

In allusion to the problem that stiffness of rolling joints is difficult to determine in theoretical modeling and analyzing of a CNC machine tool, a dynamic modeling method of the feed system is discussed, and a stiffness calculation method of the rolling joints is proposed based on the Hertz contact theory; a CNC milling machine finite element model is established, theoretical and experimental modal analysis of the workbench are conducted, theoretical vibration modes are completely in conformity with experimental vibration 

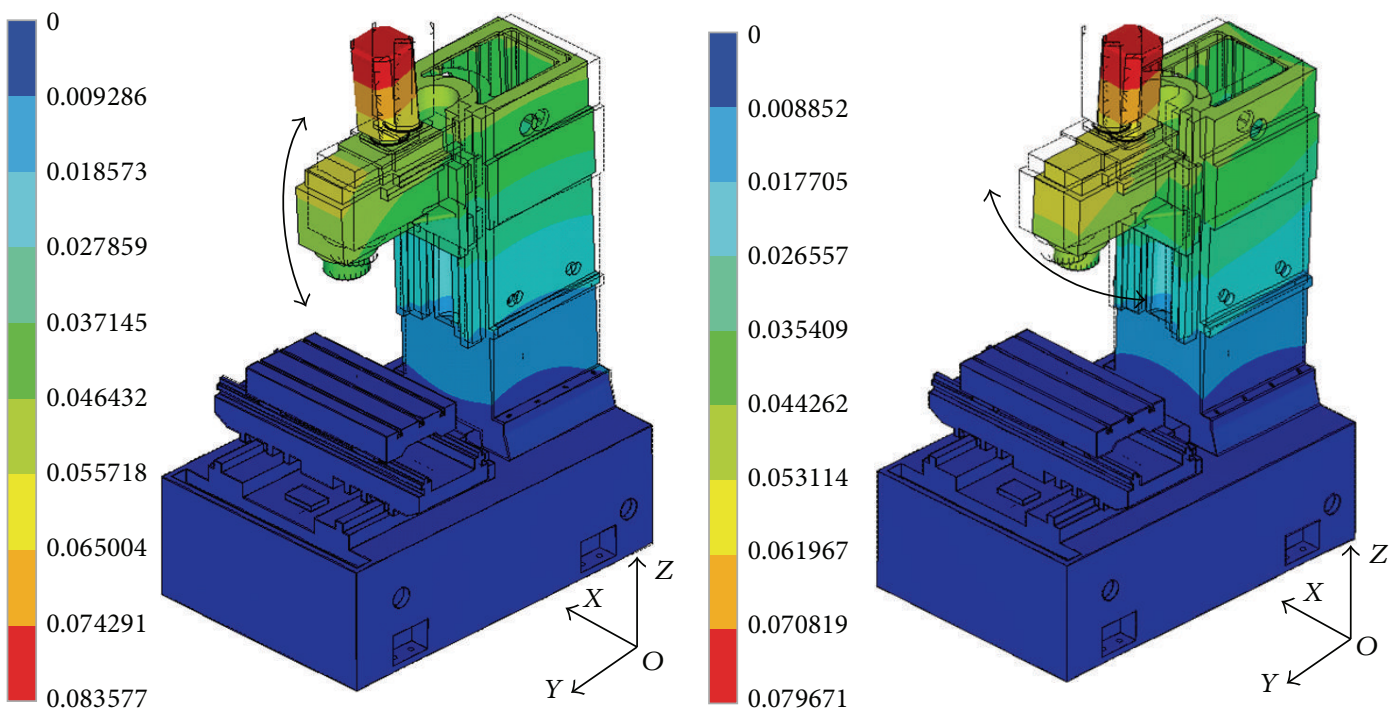

(a) The 1st vibration mode

(b) The 2nd vibration mode
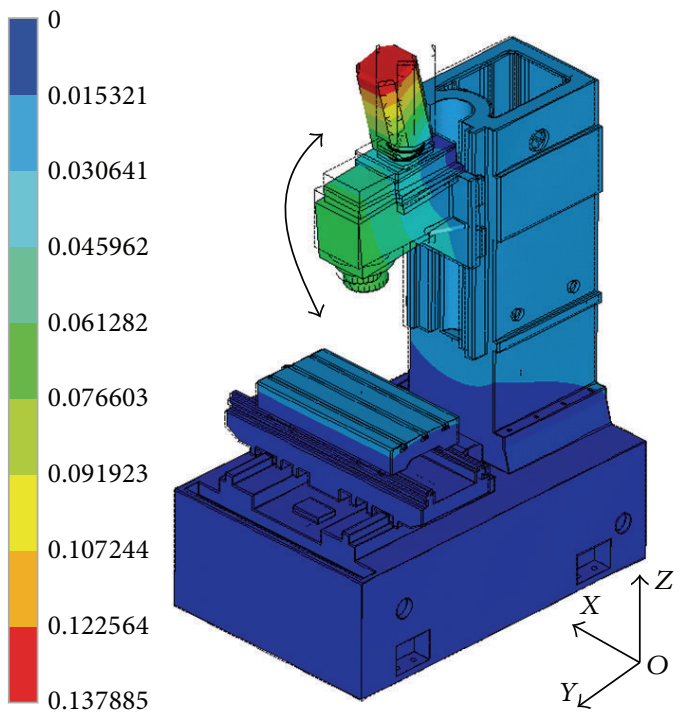

(c) The 3rd vibration mode

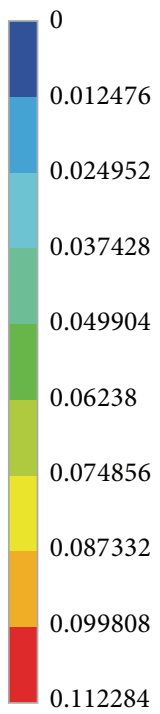

0.112284

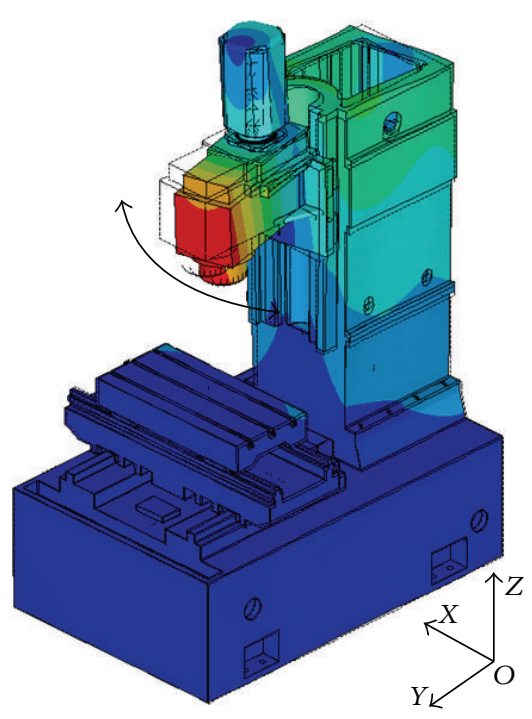

(d) The 4th vibration mode

FIGURE 16: Vibration modes of the whole machine with rigid connection.

modes, and the error between theoretical natural frequency and experimental natural frequency is within $2.92 \%$, which vertify the correctness of the finite element model and the stiffness calculation method of the rolling joints; under the two modelling methods of joints taking stiffness into consideration and connecting joints rigidly, theoretical modal analysis of the CNC milling machine is implemented, the comparison of natural frequencies and modal shapes indicates that joints' dynamic characteristic parameter is one of the key factors that influence the dynamics performance of a machine tool, and the influence is much more significant when it comes to natural frequencies and modal shapes of high orders; the proposed stiffness calculation method of the rolling joints has the advantages of accurate, reliable, and good practicability, which laid a foundation for dynamic modeling of the feed system more accurately.

\section{Conflict of Interests}

The authors declare that there is no conflict of interests regarding the publication of this paper.

\section{Acknowledgments}

The project is sponsored by the Scientific Research Foundation for the Returned Overseas Chinese Scholars, State Education Ministry (2013 no. 8), and 2014 Shanghai "Overseas Outstanding Professor." The authors would like to thank 
the editor and the reviewers for their constructive comments and suggestions which improved the quality of this paper.

\section{References}

[1] D. A. Vicente, R. L. Hecker, F. J. Villegas, and G. M. Flores, "Modeling and vibration mode analysis of a ball screw drive," The International Journal of Advanced Manufacturing Technology, vol. 58, no. 1-4, pp. 257-265, 2012.

[2] Y. Altintas, A. Verl, C. Brecher, L. Uriarte, and G. Pritschow, "Machine tool feed drives," CIRP Annals-Manufacturing Technology, vol. 60, no. 2, pp. 779-796, 2011.

[3] J. M. Zhu, T. C. Zhang, and X. R. Li, "Dynamic characteristics analysis of ball screw feed system based on stiffness characteristic of mechanical joints," Journal of Mechanical Engineering, http://www.cnki.net/kcms/detail/11.2187.TH.20141211 .0839.025.html.

[4] Y. Altintas, C. Brecher, M. Week, and S. Witt, "Virtual machine tool," CIRP Annals-Manufacturing Technology, vol. 54, no. 2, pp. 651-674, 2005.

[5] G. P. Zhang, Y. M. Huang, W. H. Shi, and W. P. Fu, "Predicting dynamic behaviours of a whole machine tool structure based on computer-aided engineering," International Journal of Machine Tools \& Manufacture, vol. 43, no. 7, pp. 699-706, 2003.

[6] S. Choi, S. Park, C.-H. Hyun, M.-S. Kim, and K.-R. Choi, "Modal parameter identification of a containment using ambient vibration measurements," Nuclear Engineering and Design, vol. 240, no. 3, pp. 453-460, 2010.

[7] K. Mao, B. Li, J. Wu, and X. Shao, "Stiffness influential factorsbased dynamic modeling and its parameter identification method of fixed joints in machine tools," International Journal of Machine Tools \& Manufacture, vol. 50, no. 2, pp. 156-164, 2010.

[8] H. Ahmadian and H. Jalali, "Identification of bolted lap joints parameters in assembled structures," Mechanical Systems and Signal Processing, vol. 21, no. 2, pp. 1041-1050, 2007.

[9] C. C. Wei and J. F. Lin, "Kinematic analysis of the ball screw mechanism considering variable contact angles and elastic deformations," Transactions of the ASME, Journal of Mechanical Design, vol. 125, no. 4, pp. 717-733, 2004.

[10] J. S. Dhupia, A. G. Ulsoy, R. Katz, and B. Powalka, "Experimental identification of the nonlinear parameters of an industrial translational guide for machine performance evaluation," Journal of Vibration and Control, vol. 14, no. 5, pp. 645-668, 2008.

[11] J. Jedrzejewski and W. Kwasny, "Modelling of angular contact ball bearings and axial displacements for high-speed spindles," CIRP Annals_Manufacturing Technology, vol. 59, no. 1, pp. 377382, 2010

[12] X. Cheng, J. F. Shi, and S. Zhang, "A study on dynamic characteristics of the joint surfaces of ball screw assembly," China Mechanical Engineering, vol. 5, no. 1, pp. 29-31, 1994.

[13] H. Zhang, J. Yuan, and Z. Wang, "Experimental research on identification of dynamic characteristic parameters of rolling guide's joint," China Mechanical Engineering, vol. 22, no. 4, pp. 415-418, 2011.

[14] R. Tiwari and V. Chakravarthy, "Simultaneous estimation of the residual unbalance and bearing dynamic parameters from the experimental data in a rotor-bearing system," Mechanism and Machine Theory, vol. 44, no. 4, pp. 792-812, 2009.

[15] P. Čermelj and M. Boltežar, "An indirect approach to investigating the dynamics of a structure containing ball bearings," Journal of Sound and Vibration, vol. 276, no. 1-2, pp. 401-417, 2004.
[16] P. Kolar, M. Sulitka, and M. Janota, "Simulation of dynamic properties of a spindle and tool system coupled with a machine tool frame," The International Journal of Advanced Manufacturing Technology, vol. 54, no. 1-4, pp. 11-20, 2011.

[17] T. Yang and C.-S. Lin, "Identifying the stiffness and damping parameters of a linear servomechanism," Mechanics Based Design of Structures and Machines, vol. 32, no. 3, pp. 283-304, 2004.

[18] B. Li, B. Luo, X. Mao, H. Cai, F. Peng, and H. Liu, "A new approach to identifying the dynamic behavior of CNC machine tools with respect to different worktable feed speeds," International Journal of Machine Tools \& Manufacture, vol. 72, pp. 7384, 2013.

[19] E. David and J. Bernard, "Simplified solution for point contact deformation between two elastic solids," Nasa Technical Memorandum, 1976. 

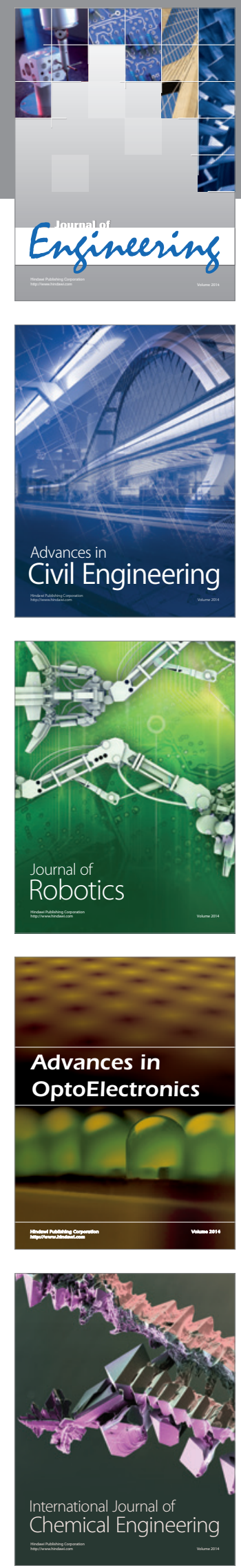

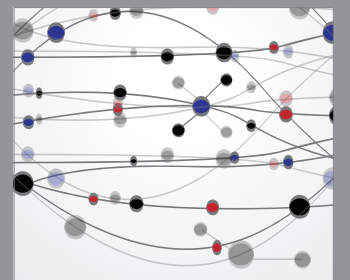

The Scientific World Journal
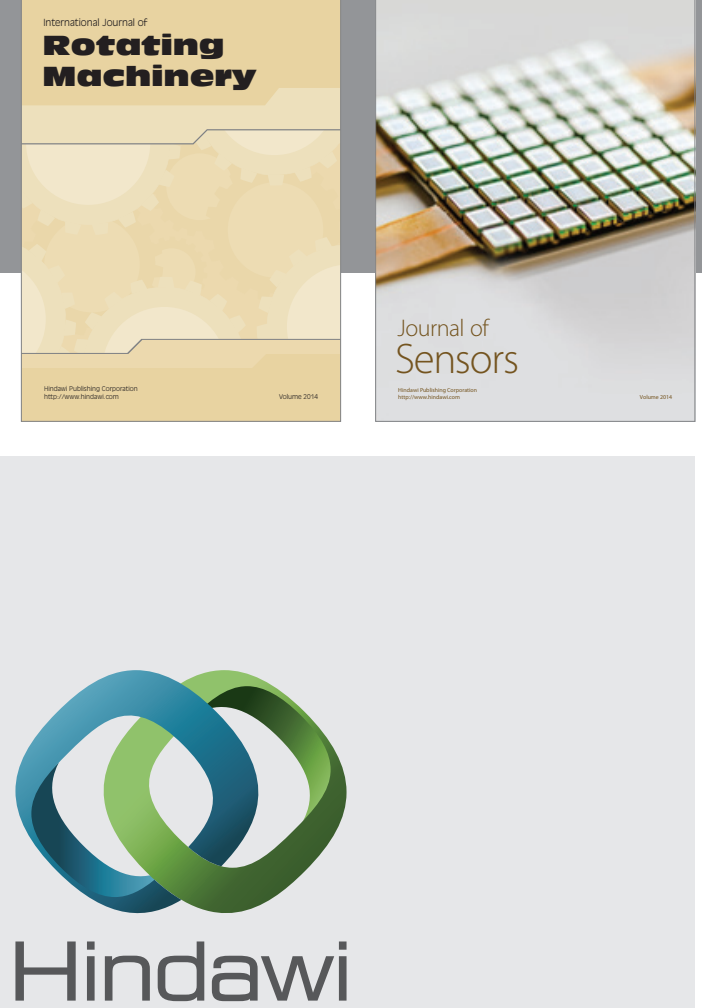

Submit your manuscripts at http://www.hindawi.com
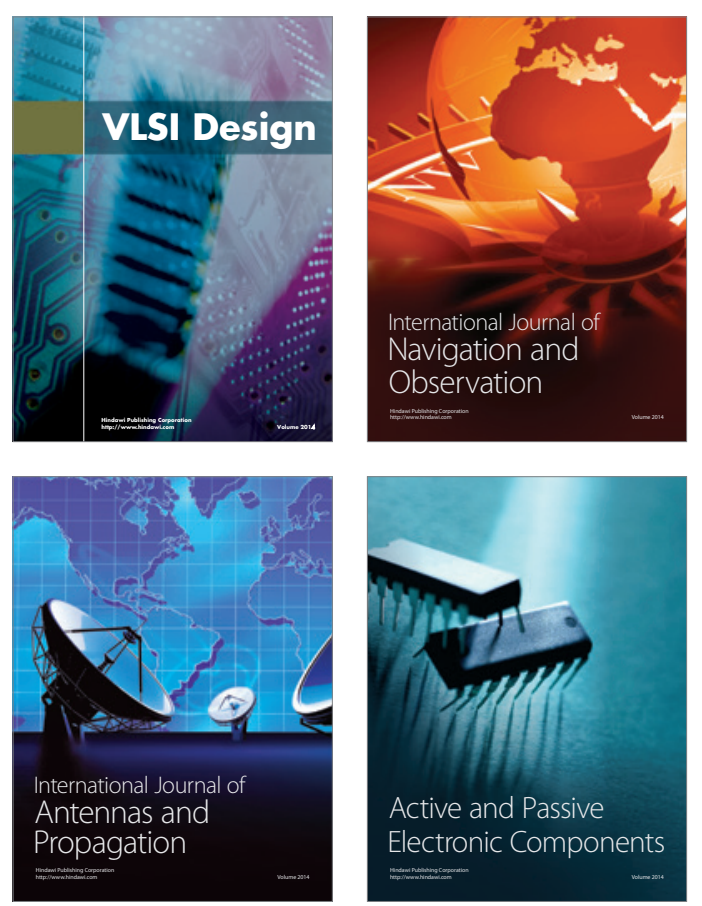
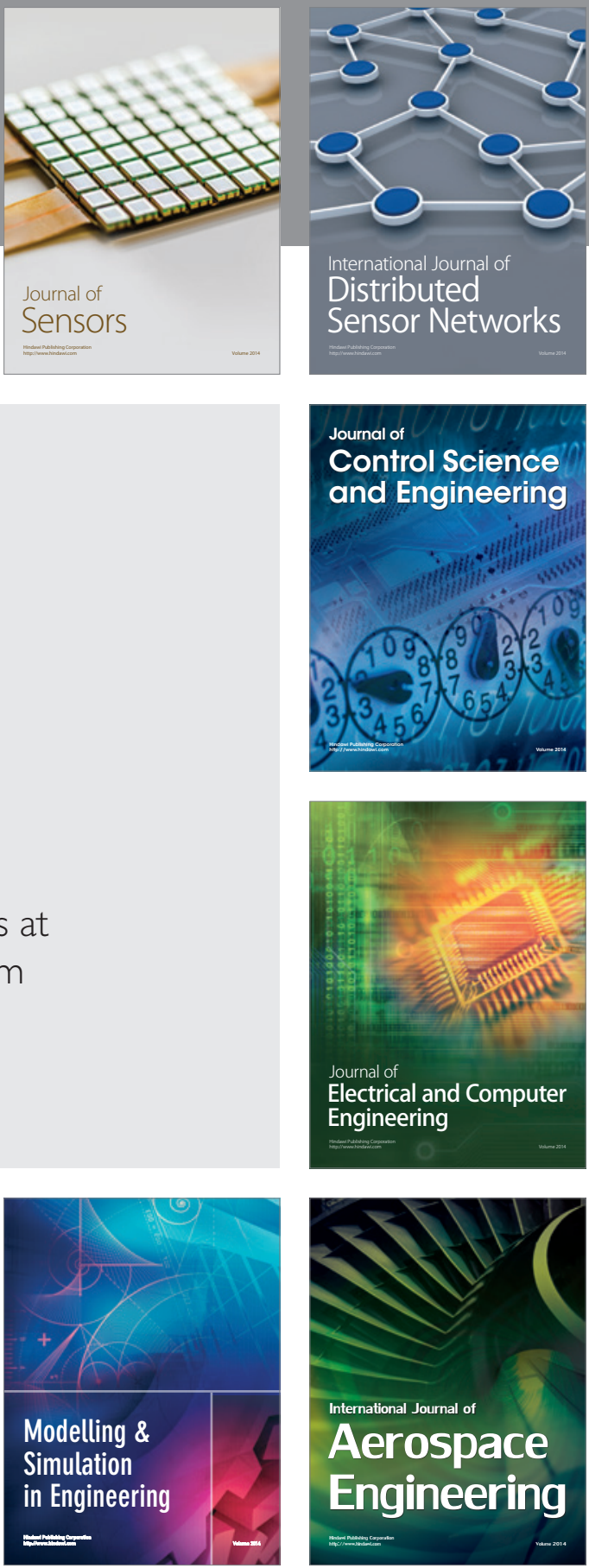

Journal of

Control Science

and Engineering
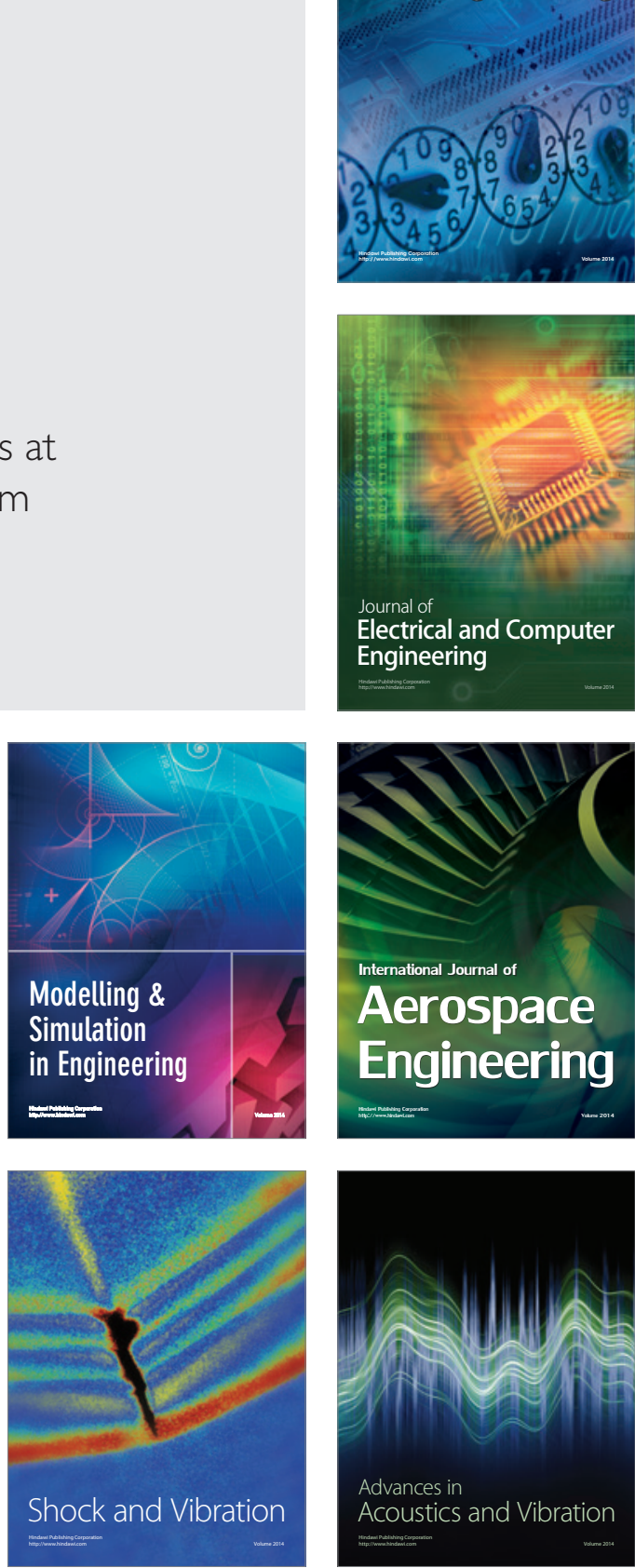